\title{
Young Lady with Acute Upper Limb Ischemia due to Cervical Band
}

\author{
$\mathrm{SK} \mathrm{GHOSH}^{\mathrm{a}}$, OS KHAN ${ }^{\mathrm{b}}$, SAN ALAM ${ }^{\mathrm{c}}$, MAFTABUDDIN ${ }^{\mathrm{d}}$, AB ADHIKARY
}

Summary:

Introduction: Acute upper limb ischemia is usually caused by compression of cervical rib on subclavian artery. But in very few cases compression may be caused by cervical band which is not evident in conventional radiography.

Results and Discussion: This is a case of a 26 year old lady, housewife, having rudimentary cervical rib, presented with acute left upper limb ischemia due to subclavian artery aneurysm. Peroperatively cervical fibrotic bandwas identified and diagnosed as the cause of subclavian artery aneurysm instead of rudimentary cervical rib. Scalenectomy, excision

\section{Introduction:}

Compression over the subclavian artery causes thoracic outlet syndrome. Arterial thoracic outlet syndrome may cause acute upper limb ischemia. It is rare, but in most of the cases compression is caused by cervical rib and is associated with subclavian artery aneurysm. In few cases, compression over the subclavian artery may occur by fibrous bands that cause acute upper limb ischemia ${ }^{1}$. Cervical band is usually not visible inconventional radiography and mostly diagnosed per-

a. Dr. Shantonu Kumar Ghosh, Resident (Cardiovascular and Thoracic Surgery), Bangabandhu Sheikh Mujib Medical University, Shahbagh, Dhaka.

b. Dr. Omar Sadeque Khan, Medical Officer, Department of Cardiac Surgery, Bangabandhu Sheikh Mujib Medical University, Shahbagh, Dhaka.

c. Dr. Saleh Ahmed Nurul Alam, Associate Professor and Head, Department of Vascular Surgery, National Institute of Cardiovascular Diseases, Sher-e-Bangla Nagar, Dhaka.

d. Prof. Mohammad Aftabuddin, Professor and Chairman, Department of Cardiac Surgery, Bangabandhu Sheikh Mujib Medical University, Shahbagh, Dhaka.

e. Prof. Asit Baran Adhikary, Professor, Department of Cardiac Surgery, Bangabandhu Sheikh Mujib Medical University, Shahbagh, Dhaka.

Address of Correspondence: Prof. Mohammad Aftabuddin, Chairman, Department of Cardiac Surgery, Room: 1203, Block: D, Bangabandhu Sheikh Mujib Medical University, Shahbagh, Dhaka. Telephone: Office- +880-2-9661438, Mobile- +8801711-677713, E-mail: aftab12uddin@yahoo.com

Received: 28 April, 2014

Accepted: 18 Dec., 2014 of the cervical band, excision of the aneurysmsac and arterial reconstruction of the subclavian artery was performed. Her operation was uneventful, postoperative recovery was excellent. She was discharged to home on $4^{\text {th }}$ postoperative day ensuring good distal pulsation of affected limb.

Conclusion: Though rare, cervical band is a cause of acute upper limb ischemia. So, we must not forget while diagnosing this type of cases.

Key Words: Cervical fibrotic band,Cervical rib,Subclavian artery aneurysm

(J Banagladesh Coll Phys Surg 2015; 33: 101-104)

operatively. In this case report we present a young woman with rudimentary cervical rib who suddenly developed acute upper limb ischemia due to cervical band.

\section{Case Report:}

A 23 year old woman, normotensive, nondiabetic housewife, presented with pain and tingling in left upper limb for 3 months and blackening in distal part of left hand for 2 months. Pain at first started at pulp of the left hand, used to persist for 1-2 days and subsided by taking medicine. Gradually pain had spread up to palm, then proximally towards forearm and arm. Blackening began at tip of the fingers and was limited there. She also noticed sensory impairment at distal hand and fingers. She gave no history of smoking or taking oral contraceptive pills. She used to do normal household works.

On examination, her pulse was 80beats/min, regular with normal volume andblood pressure was $110 / 70 \mathrm{~mm}$ of Hg. On examination of left upper limb,there was no gross muscle wasting. Colour of skin of left upper limb was normal except the tip of fingers which were black. Local temperature of the left forearm and hand was cooler than that of right. But temperature of arm was normal. Bulk and power of muscles of left upper limb was normal. Though motor function was intact, there was diminished sensation of left fingers. Pulsation was felt over left supraclavicular fossa. Left axillary pulse was palpable with normal volume and quality. Left brachial, radial and 
ulnar pulses were not palpable. Bruit was heard over left supraclavicular fossa. Other systemic examination revealed normal findings. Her hemoglobin was $12.6 \mathrm{gm} /$ dl, ESR was $26 \mathrm{~mm}$ in $1^{\text {st }}$ hour, C-reactiveprotein was 1.6 $\mathrm{mg} / \mathrm{dl}$. ELISA test for ANA was negative. Duplex study of the left upper limb revealed arterial thromboses involving distal end of the axillary, whole length of brachial, ulnar and radial arteries up to the level of wrist.X-Ray Cervical Spine (B/V) reported left sided rudimentary cervical rib (Figure 1). CT Aortogram with left upper limb angiogram was done (Figure 2). Findings were, ascending aorta and arch of the aorta appeared normal with normal branching pattern. Focal aneurysmal dilatation of $2^{\text {nd }}$ part of the left subclavian artery for a length of about $20 \mathrm{~mm}$ and diameter was about $10.2 \mathrm{~mm}$. Thrombus within left axillary and brachial artery having faint flow in forearm arteries. MRI of neck reported no cervical rib or band. Since admission patient received medical management including Clopidogrel-Aspirin combination and Warferin. As there was diagnostic dilemma and clinical condition of the patient was not improving, surgery was planned to explore the cause and for arterial reconstruction of thesubclavian artery aneurysm.

The patient was in supine position. After she was under general anaesthesia, a sand bag was placed under her left shoulder to expose the operation field properly. Two fingers above the left clavicle a supraclavicular incision was made from lateral border of the starnoclidomastoid muscle anteriorly upto anterior border of the trapezius muscle posteriorly. The scalene fat pad was mobilized and the anterior scalene muscle was excised preserving the phrenic nerve. The left subclavian artery aneurysm was identified and exposed.Proximal and distal control of the subclavian artery was taken and the artery was retracted downwards. Systemic heparinization was done. A whitish, glistening fibrous band was identified (Figure 3).The band was dissected. After doing the subclavian arteriotomy,Fogarty embolectomywas done upto the mid arm. Good distal flow was found. Excision of the aneurysm sac was done. Arteriotomywas closed with 6/0 prolene. Haemostasiswas ensured and wound was closed in layers keeping a drain in situ. Early postoperative period was smooth and uneventful. Heparin was continued as 2500 units subcutaneously 8 hourly. On $1^{\text {st }}$ post-operative day, the drain was removed. Distal limb was warm and blackening of the finger tips found diminishing. On $2^{\text {nd }}$ post-operative day both radial and ulnar pulses were palpable with good quality. On $4^{\text {th }}$ post-operative day, patient was discharged from hospital with advices of cutting the stiches at surgery department of local hospital after 4 days, to take Clopidogrel-Aspirin combination daily for at least 3 months and to come for follow up at vascular surgery outpatient department after 1 month.

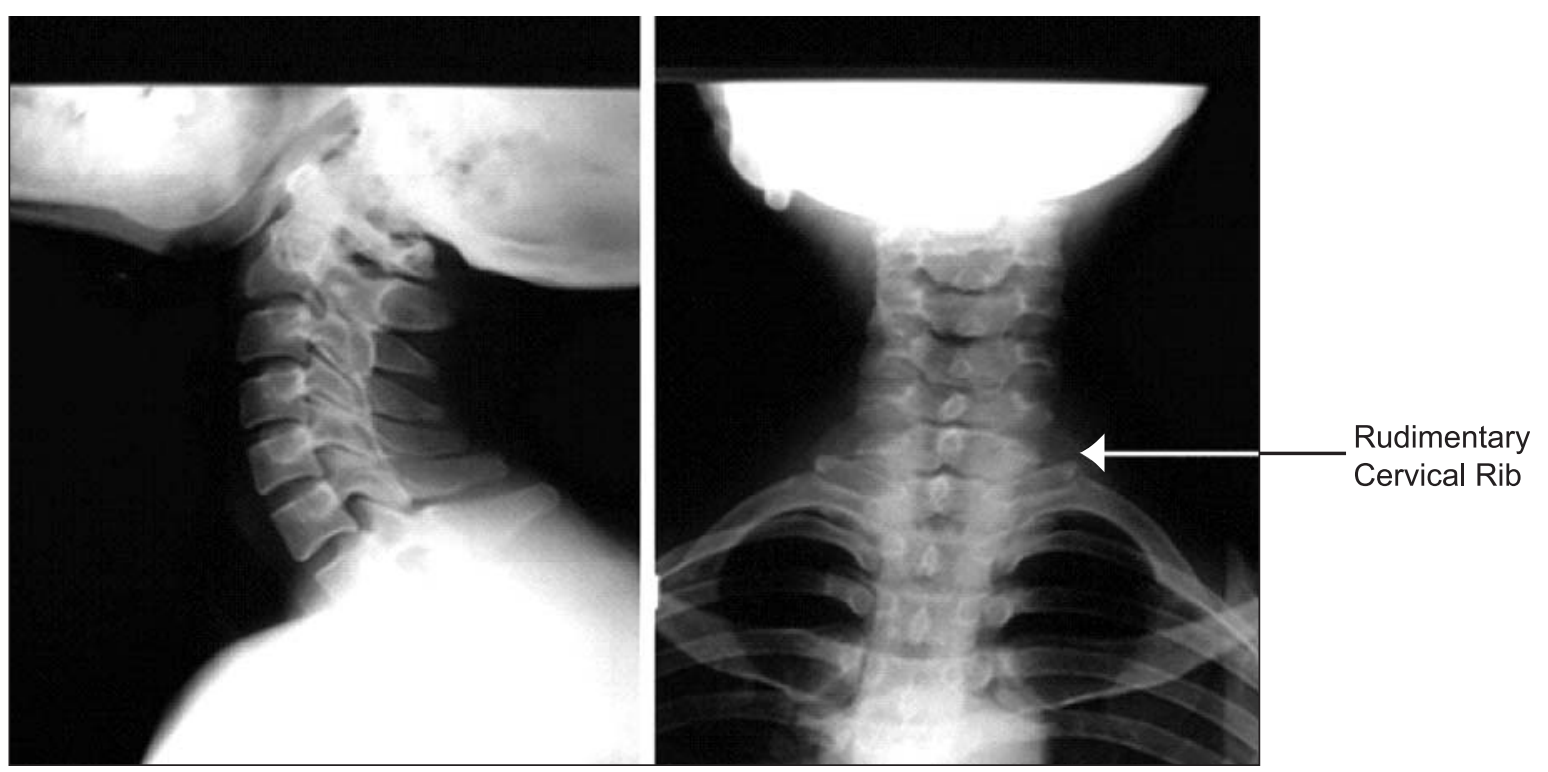

Fig.-1: X-ray cervical spines of the patient showing left sided rudimentary cervical rib. 


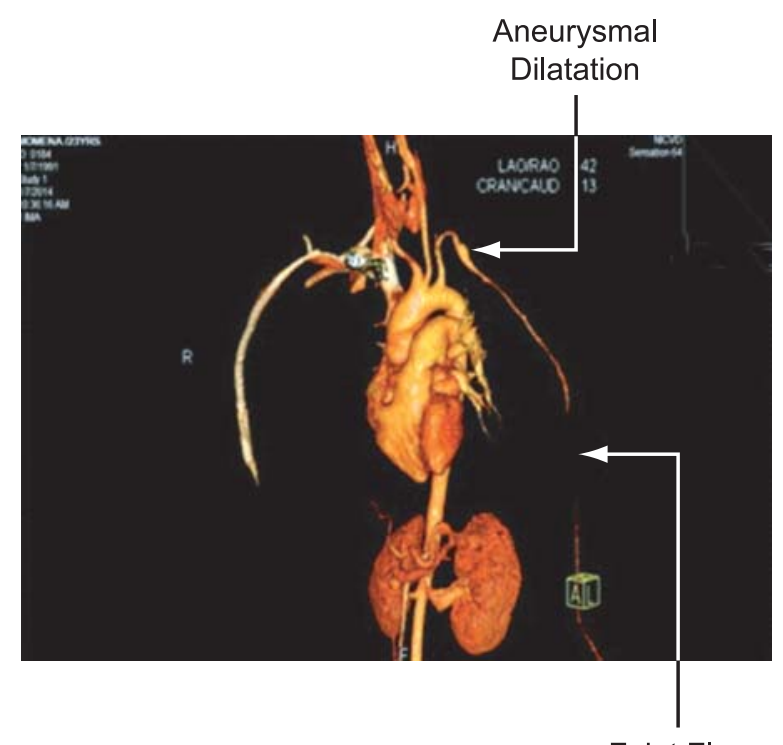

Faint Flow

Fig.- 2: CT angiogram of the patient reported focal aneurysmal dilatation of $2^{\text {nd }}$ part of the left subclavian artery. Thrombus within the left axillary and brachial artery having faint flow in forearm arteries.

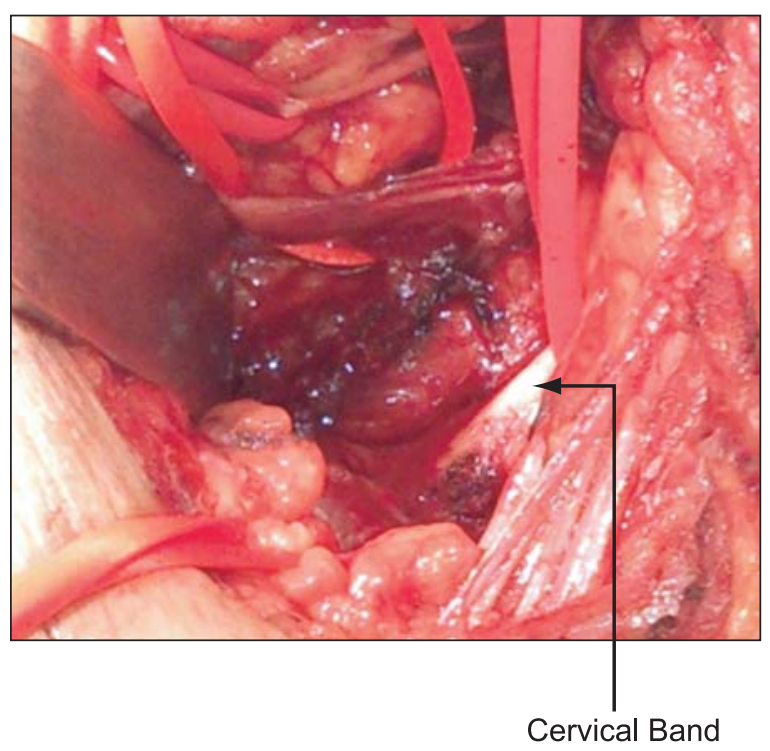

Fig.- 3: Per-operative finding of the patient was presence of cervical band.

\section{Discussion:}

Arterial complications following the subclavian artery compression represent a type of Thoracic Outlet Syndrome (TOS). The term Thoracic Outlet Syndrome
(TOS) was first introduced by Peet et al. in $1956^{2}$. Manifestations of arterial TOS represent a progressive course characterized by extrinsic compression, poststenotic dilatation, aneurysmal degeneration and secondary embolization ${ }^{3}$. Among the course of neurovascular structures from the base of the neck into the arm via the axilla, the most important narrow passageway is the interscalene triangle. Its boundaries are the anterior scalene muscle anteriorly, the middle scalene muscle posteriorly and the medial surface of the first rib inferiorlyt .

In most of the cases arterial complications of TOS is caused by cervical ribs in the interscalene triangle. Less common causes include anomalous first ribs, fibrocartilaginous bands associated with the anterior scalene muscle and hypertrophic callus from healed cervical fractures ${ }^{1}$. This push the subclavian artery forward, where it is compressed between the first rib and the anterior scalene muscle. This compression causes injury to the inferior aspect of the third segment of the subclavian artery which may lead to localized intimal damage or post-stenotic dilatation. This dilatation may progress to aneurysmal change and localized intimal damage may lead to embolization or thrombosis. In our case, aneurysmal dilatation of subclavian artery was due to above mentioned mechanism.

Among the anatomic abnormalities causing arterial TOS, cervical rib comprises $63 \%$, anomalous $1^{\text {st }}$ rib $22 \%$, fibrocartilagenous band $10 \%$, clavicular fracture $4 \%$ and enlarged C7 transverse process $1 \%{ }^{3}$.Sanders and Haug have reported that up to $12 \%$ of patients with arterial TOS have fibrous bands without any definable arterial abnormalityu .In this case, it was also for the fibrous band like Sanders and Haug's finding. Most patients with symptomatic arterial TOS are young with mean age 37 years, with equal proportion of male and female $e^{3}$.Our patient was 36 years aged young lady. Fibrocartilagenous bands may occur due to fibrosis of the muscles. Common bands are middle scalene muscle band, outlet band and anterior scalene muscle band. In the complete form cervical rib articulates with the manubrium or the first rib. In some cases a relatively short bony cervical rib can be extended by fibrous bands which are not visible by conventional radiography but can cause pathology identical to that of a complete bony cervical ribv . It may be diagnosed per-operatively by 
direct observation and feeling of the band. Our case was also diagnosed during operation.

The first successful treatment of a subclavian artery aneurysm was achieved in 1864 by Smyth in New Orleans, who ligated the right common carotid artery and the innominate arteryw .The three main components of treatment include relieving the arterial compression, removing the source of embolus and restoring the distal circulationx .Our surgical treatment was like Smith and Valentine. Relieving the arterial compression involves routine division of anterior scalene muscle and excision of cervical rib or fibrous band.Resecting a subclavian aneurysm or repairing an arterial stenosis with intimal damage removes the source of embolus. Restoring the distal circulation involve thrombolysis, thromboembolectomy or bypass.

\section{Conclusion:}

While diagnosing a case of acute upper limb ischemia, one must not forget about fibrous band as a cause of compression over subclavian artery along with cervical rib.As fibrosis is usually not evident by conventional radiography, diagnosis may be difficult. This is a rare conditionbut more common in younger age. Person with cervical rib or cervical band fibrosis, doing physical exercise or carrying weight, are at increased risk of developing arterial thoracic outlet syndrome. Early diagnosis and management is essential to save the limb from necrosis following acute limb ischemia.

\section{References:}

1. Ciampi P, Scotti C, Gerevini S, Cobelli FD, Chiesa R, Fraschini $G$ et al. Surgical treatment of thoracic outlet syndrome in young adults: single centre experience with minimum three-year follow-up. International Orthopaedics (SICOT). 2011;35:1179-1186.

2. Peet RM, Henriksen JD, Anderson TP, Martin GM. Thoracic outlet syndrome: Evaluation of therapeutic exercise programme. Mayo Clin Proc. 1956;31:281-283.

3. Smith ST, Valentine RJ. Thoracic Outlet Syndrome: Arterial. In: Cronenwett JL, Johnston KW, editors. Rutherford's vascular surgery. $7^{\mathrm{TH}}$ ed. Philadelphia:Saunders Elsevier,2010; p.2128-2136.

4. Abdul-Jabar H, Rashid A, Lam F. Thoracic Outlet Syndrome. Orthopedics and trauma [serial online].2008 [cited 2009 Feb]23:69-73. Available from: http:// www.orthopaedicsandtraumajournal.co.uk/article/S18771327\%2808\%2900200-5.

5. Tam K, Seneviratne K, Pathak R, Jayatunga A. An acutely ischemic hand in a young adult due to subclavian artery aneurysm (SAA) caused by a cervical rib: a case report. Cases Journal 2008, 1:140 doi:10.1186/1757-1626-1140. Available from: http://www.casesjournal.com/content/ $1 / 1 / 140$.

6. Kemp CD, Rushing GD, Rodic N, McCarthy E, Yang SC. Thoracic outlet syndrome caused by fibrous dysplasia of the first rib. Ann Thorac Surg. Mar 2012; 93(3): 994-996.

7. TimaranC. H. Upper extremity aneurysms. In: Cronenwett JL, Johnston KW, editors. Rutherford's vascular surgery. $7^{\mathrm{TH}}$ ed. Philadelphia: Saunders Elsevier,2010; p.2128-2136.

8. Chang KZ, Likes K, Davis K, Demos J, Freischlay JA.The significance of cervical ribs in thoracic outlet syndrome. Journal of vascular surgery: official publication, the Society for Vascular Surgery (and) International Society for Cardiovascular Surgery, North American Chapter 03/ 2013; 57 (3):771-775. - 3.52 Impact Factor. 